\title{
Pace making and worker reassignment for assembly line rebalancing
}

\author{
Gerçek Budak $^{1} \cdot$ Xin Chen $^{1}$ (I)
}

Received: 17 April 2020 / Accepted: 19 August 2020 / Published online: 28 August 2020

(c) Springer Nature Switzerland AG 2020

\begin{abstract}
The objective of this article is to develop a mathematical model that helps foremen rebalance assembly lines in real time. Assembly lines with a large number of workstations go through extensive line balancing to determine production rates. Once production begins, one or more workstations may not operate at predetermined production rates due to disturbances, and the assembly line requires rebalancing. Previous research largely focused on task reassignment for rebalancing. Effective and efficient tools for real-time line rebalancing are needed. This research focuses on rebalancing of unpaced and asynchronous assembly lines through pace making and worker reassignment. A mixed integer programming model is developed and its optimal solution determines which workstations pace up (increase production rates) and the amount of increase, which workstations pace down (decrease production rates) and the amount of decrease, and whether workers from certain workstations are reassigned to work at other workstations to decrease the production rates of the former and increase the production rates of the latter. Foremen may use these recommendations to rebalance assembly lines by adjusting production rates and reassigning workers. Numerical results show that the solution time of the model is less than one second, which enables real-time line rebalancing for large assembly lines.
\end{abstract}

Keywords Assembly line rebalancing · Mixed integer programming $\cdot$ Pace making $\cdot$ Unpaced and asynchronous assembly line $\cdot$ Worker reassignment

\section{Introduction}

Assembly lines have been in use for decades and are ubiquitous in today's manufacturing and production systems. As more and more products transition from mass production (make-to-stock) to mass customization (make-toorder), balancing of assembly lines aims to meet customers' demand and reduce production cost. Assembly line balancing is one of the most important decisions for largescale production. Becker and Scholl [6] defined line balancing as assigning tasks to workstations to balance workload. Kara et al. [15] suggested several objectives of line balancing (e.g., minimizing total cost and difference in workload for workstations and maximizing production rate). There are many variations and extensions of the classical line balancing problem [6-9]. This paper investigates a common yet challenging problem that foremen of assembly lines face on a regular basis: whether and how workers in an assembly line pace up or pace down to adjust production rates and are reassigned to different workstations if the assembly line does not operate at the production rates determined in line balancing.

When operations of an assembly line deviate from the prescribed parameters determined in line balancing, the assembly line must be rebalanced to minimize the impact caused by worker fatigue and lack of motivation, extra machine setup time, material shortage, machine breakdowns, or other disturbances. Rebalancing of assembly lines occurs in almost every production facility that owns a flow-based production $[2,36]$. Foremen of assembly lines are responsible for rebalancing [33]. The main contribution of this study is the mathematical model and its solutions

$\triangle$ Xin Chen, xchen@siue.edu; Gerçek Budak, gbudak@siue.edu| ${ }^{1}$ Department of Industrial Engineering, School of Engineering, Southern Illinois University, Edwardsville, IL 62026-1805, USA. 
that provide an effective and efficient tool for foremen to make real-time decisions for pace making and worker reassignment in assembly lines.

In line balancing [31], each workstation is assigned a set of tasks and a fixed amount of time to complete each task. Once production begins, however, various disturbances occur and the assembly line needs to be rebalanced in response to disturbances. Certain disturbances (e.g., workstation breakdowns and shortage of supplies) pose hard constraints on a production system; they are not resolved through rebalancing of workstations and should be taken into account in the line balancing analysis [6]. Some disturbances such as skilled workers completing tasks faster than expected would cause a queue at downstream workstations. Other disturbances such as worker slowdowns due to fatigue may cause a queue at upstream workstations. These disturbances may be addressed by pace making and reassigning workers so that the assembly line is restored to the production plan determined in line balancing.

This study investigates the short-term line rebalancing problems in which real-time decisions are made in response to disturbances such as out-of-capacity buffers, worker slowdowns, and idle workstations. These disturbances either increase the cycle time of a paced or an unpaced but synchronous assembly line, or decrease the throughput of an unpaced and asynchronous assembly line [8]. The goal of rebalancing is to minimize the impact of disturbances by adjusting production rates (pacing up or pacing down) and reassigning workers between workstations. To the best of the authors' knowledge, this paper is the first study that focuses on pace making and worker reassignment for assembly line rebalancing.

In a paced or an unpaced but synchronous assembly line, an automated material handling system (e.g., a conveyor) is used to transfer parts and products from one workstation to the other. Workers in these assembly lines are stationed at their assigned workstations. Other limitations (e.g., limited space) also prevent the assembly line from reassigning workers to different workstations. This study aims to determine pace making and worker reassignment in unpaced and asynchronous assembly lines in which workers can be reassigned to different workstations to improve the throughput when disturbances occur. The specific goal of line rebalancing in this study is to increase or decrease production rates of workstations, and therefore improve the throughput of the entire assembly line and minimize the impact of disturbances.

While many studies (e.g., $[16,22,38]$ focused on reassigning tasks to different workstations to rebalance assembly lines, there is little research on pace making and worker reassignment. Table 1 is a comparative analysis of recent literature about line balancing and rebalancing. $A$ most common objective of these studies is to minimize workload. Some new constraints described in the studies include idle time, task reassignment, saturation limit, and retraining cost. This paper bridges the gap between realtime line rebalancing and worker reassignment. The rest of this paper is organized as follows: Sect. 2 describes related literature, Sect. 3 illustrates in detail the mathematical model for real-time line rebalancing, Sect. 4 validates the mathematical model with numerical studies, and Sect. 5 concludes the paper with discussion and future research.

Table 1 Comparative analysis of recent literature

\begin{tabular}{|c|c|c|}
\hline Literature & Objective functions & New constraints proposed \\
\hline $\begin{array}{l}\text { [1], "An expert system to minimize operational } \\
\text { costs in mixed-model sequencing problems } \\
\text { with activity factor" }\end{array}$ & $\begin{array}{l}\text { Minimize total production loss due to } \\
\text { work overload and idle time }\end{array}$ & $\begin{array}{l}\text { Idle time: the difference between available pro- } \\
\text { cessing time and applied processing time }\end{array}$ \\
\hline $\begin{array}{l}\text { [2], "Iterated local search for dynamic assembly } \\
\text { line rebalancing problem" }\end{array}$ & $\begin{array}{l}\text { Minimize the maximum workload } \\
\text { among workstations }\end{array}$ & $\begin{array}{l}\text { Task reassignment: a task may be reassigned } \\
\text { from one workstation to another }\end{array}$ \\
\hline $\begin{array}{l}\text { [3], "Workforce minimization for a mixed- } \\
\text { model assembly line in the automotive } \\
\text { industry" }\end{array}$ & Minimize the number of workers & $\begin{array}{l}\text { Worker task assignment: a worker can start a } \\
\text { new task after the completion of the current } \\
\text { task }\end{array}$ \\
\hline $\begin{array}{l}\text { [5], "Consideration of human resources in the } \\
\text { Mixed-model Sequencing Problem with } \\
\text { Work Overload Minimization: Legal provi- } \\
\text { sions and productivity improvement" }\end{array}$ & Minimize total work overload & $\begin{array}{l}\text { Saturation limit: relationship between time used } \\
\text { by the operator to carry out workload and the } \\
\text { available time to work }\end{array}$ \\
\hline $\begin{array}{l}\text { [18], "A comparative study of exact methods } \\
\text { for the simple assembly line balancing } \\
\text { problem" }\end{array}$ & $\begin{array}{l}\text { Minimize the number of workstations; } \\
\text { Minimize the cycle time; } \\
\text { Maximize the line efficiency }\end{array}$ & Not applicable \\
\hline $\begin{array}{l}\text { [36], “A multi-objective genetic algorithm for } \\
\text { mixed-model assembly line rebalancing" }\end{array}$ & $\begin{array}{l}\text { Minimize the number of workstations; } \\
\text { Minimize workload variation; } \\
\text { Minimize retraining cost of the operators }\end{array}$ & Retraining cost: one task at one workstation \\
\hline
\end{tabular}




\section{Background}

Many studies about line balancing focus on planning for manufacturing systems. Relatively few studies were conducted to investigate line balancing for service systems [25] and reconfiguration or rebalancing of assembly lines after disturbances occur $[2,16,22,38]$. The requirement for line rebalancing changes in response to different disturbances. Significant changes of a production line (e.g., introduction of new products) require rebalancing, which is a long-term decision and equivalent to a typical line balancing problem. Other disturbances, such as significant changes in production demands and the need to remove or add workstations [13], also require line rebalancing. These mid- to long-term decisions [8] are similar to the classical line balancing problems; these decisions are valid for at least a few months and are not made frequently.

Short-term line rebalancing decisions include reassignment of workers, tasks, or supplies to different workstations, adjustment of production rates (pacing up or down within the upper and lower limits), and modification of production parameters (e.g., speed of a conveyor or capacity of a buffer). Once disturbances are resolved, the assembly line may be rebalanced to restore its original cycle time or throughput. These short-term rebalancing decisions must be made in real time in response to frequent disturbances in assembly lines. Most studies (e.g., $[16,22,38]$ on rebalancing focus on reassigning tasks to different workstations.

For both line balancing and rebalancing problems, mathematical models may be formulated and a good or optimal solution is computed to determine task assignments for workstations and the sequence of models for mixed-model assembly lines [9, 11, 24]. In line balancing problems, long-term decisions such as the workstation layout (e.g., straight and U-shaped), number of workstations, material handling systems, and others need to be made. In line rebalancing problem, part of an assembly line may be affected by frequent disturbances and quick decisions need to be made to minimize the impact.

Line balancing focuses more on mid- and long-term decisions. Line rebalancing focuses more on short-term decisions. Line balancing problems have more decision variables than rebalancing problems. Rebalancing problems must be solved within a short amount of time, whereas line balancing problems usually allow sufficient time to find an optimal solution.

\subsection{Challenges in line balancing}

Numerous studies were conducted to solve line balancing problems. For example, both branch and bound (e.g.,
[17] and dynamic programming may be used to find exact solutions for simple [18, 30,34] and generalized assembly line balancing problems [6]. Heuristic algorithms (e.g., [19, $21,35,37]$ were used to solve line balancing problems. The objectives of various studies include maximization of profit [29], minimization of cycle time [28], work force minimization [3], and ergonomics [4, 27].

There are two main challenges related to task times in line balancing problems. First, optimal solutions to line balancing are sensitive to changes in task times [16]. Many optimal solutions are unstable; they are not optimal when there are slight changes in actual task times. Secondly, task times are not deterministic and may change depending on worker competence [20], learning effects [8, 32], training [7], and other factors. The assumption that task times remain the same is unrealistic and does not always hold. More important, many controllable or uncontrollable factors may change in a production or service system, and line rebalancing is imperative in responding to these changes.

\subsection{Scope of line rebalancing}

Previous studies (e.g., [26] show that an assembly line is more efficient with a paced configuration than an unpaced setting when the assembly line is short and a single model is produced. For a long mixed-model assembly line, an unpaced setting is more efficient than a paced setting [26]. Mixed-model assembly lines are much more prevalent than single-model or multi-model assembly lines because of mass customization [5]. Since paced assembly lines often use automated material handling (e.g., conveyor systems) and specialized workstations, it is more difficult to reassign resources (e.g., tasks and workers) in paced than in unpaced assembly lines.

Available studies (e.g., $[16,22,38]$ perform line rebalancing through task reassignment or workstation reduction. These rebalancing decisions require changes in assembly line hardware and may be costly and infeasible in many situations. Although several studies (e.g., $[7,8,20]$ investigated how line rebalancing may be affected by workers' performance, there is a gap between worker reassignment and line rebalancing, which is the focus of this paper. Many unpaced production (e.g., assembly of appliances; [22] and service lines (e.g., fast-food restaurants) require frequent rebalancing, and reassignment of workers is often the only feasible solution.

This study investigates the short-time line rebalancing problems in which real-time decisions are made in response to disturbances such as out-of-capacity buffers, worker slowdowns, and idle workstations. These disturbances decrease the throughput of an unpaced and asynchronous assembly line. The goal of rebalancing 
is to minimize the impact of disturbances by adjusting production rates (pacing up or pacing down) and reassigning workers between workstations. To the best of the authors' knowledge, this is the first study that focuses on pace making and worker reassignment for assembly line rebalancing.

\section{Mathematical modeling}

Line rebalancing is a complex problem for an assembly line with multiple workstations and workers. Foremen of an assembly line need to adjust production rates and assign workers for a large number of workstations in real time. One of the main objectives of this research is to develop a mathematical model that provides the optimal solution to minimize the impact of disturbances on the throughput of unpaced and asynchronous assembly lines.

\subsection{Assumptions}

This study investigates the short-time line rebalancing problems for unpaced and asynchronous assembly lines.
In line balancing, many decisions such as the number of workstations for a set of tasks, number of workers for each workstation, asynchronous flow of jobs, precedence between tasks, buffer space, and material handling equipment are made so that workload are balanced among workstations. Line rebalancing takes these decisions made in line balancing as input and aims to adjust production rates of workstations to keep the throughput of the assembly line at the target level when disturbances occur. Shortterm line rebalancing does not add or eliminate workstations, adjust the flow of jobs, or change the precedence between tasks.

\subsection{Mathematical model}

Table 2 summarizes parameters and variables in the mathematical model. The values of parameters are obtained from line balancing or during production. Foremen do not determine the values of parameters, which are input to the mathematical model. $S_{i}$ and $R_{i}$ in Table 2 represent predetermined (line balancing) and actual production rates of the $i^{\text {th }}$ workstation, respectively. $n_{i}$ is the slack in production rate when $R_{i}$ is less than $S_{i}, n_{i}=S_{i}-R_{i} ; n_{i}=0$

Table 2 Parameters and variables of the mathematical model

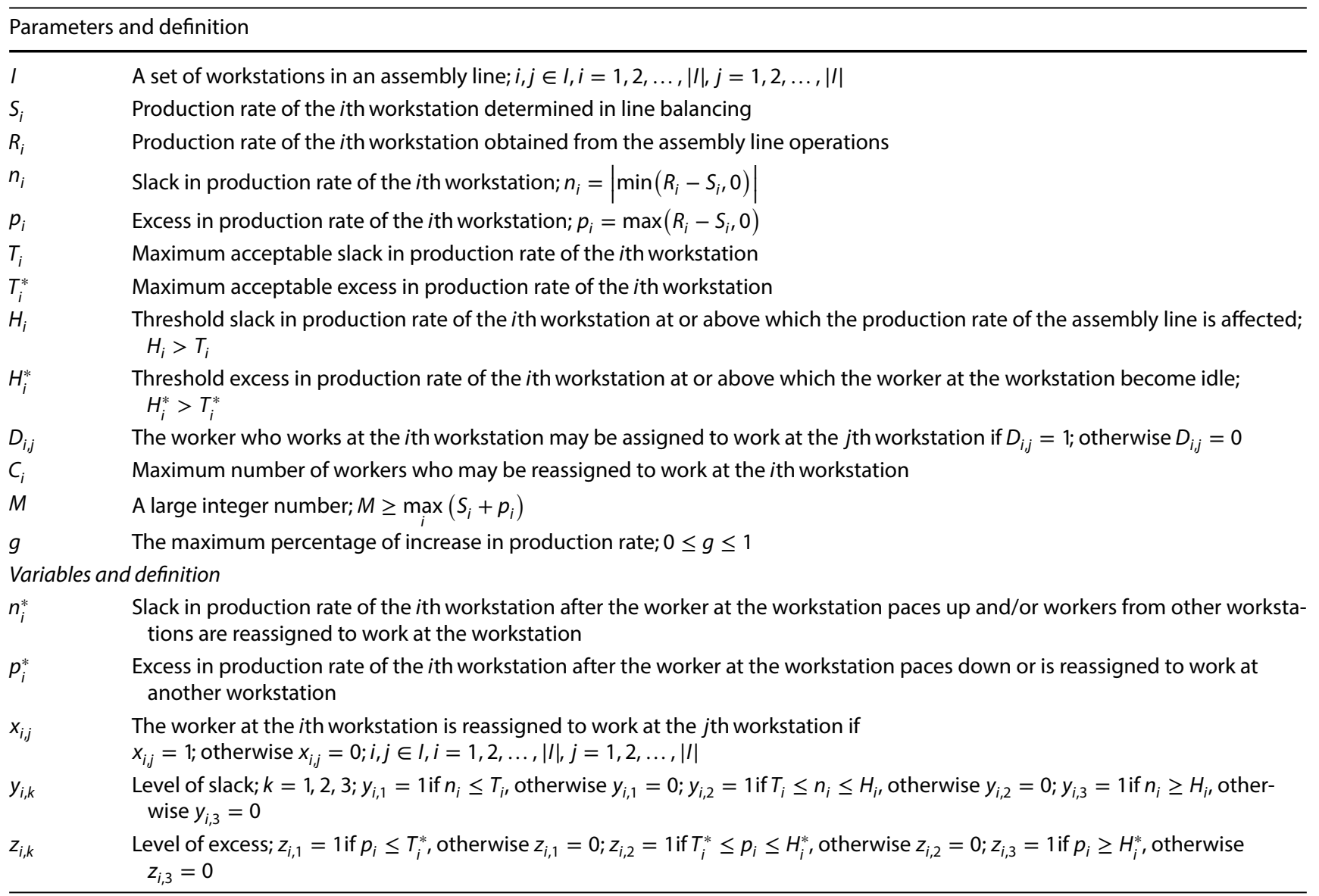


otherwise. $p_{i}$ is the excess in production rate when $R_{i}$ is greater than $S_{i}, p_{i}=R_{i}-S_{i} ; p_{i}=0$ otherwise.

$T_{i}$ and $T_{i}^{*}$ in Table 2 are the maximum acceptable slack and excess, respectively, in the production rate of the $i$ th workstation. $H_{i}$ and $H_{i}^{*}$ are the threshold slack and excess, respectively, in the production rate of the $i$ th workstation. No actions are required if $n_{i} \leq T_{i}$ and $p_{i} \leq T_{i}^{*}$. If $T_{i} \leq n_{i} \leq H_{i}$ or $T_{i}^{*} \leq p_{i} \leq H_{i}^{*}$, foremen will be provided with an alert and may request the worker at the ith workstation to pace up if $T_{i} \leq n_{i} \leq H_{i}$ or pace down if $T_{i}^{*} \leq p_{i} \leq H_{i}^{*}$. If $n_{i} \geq H_{i}$ or $p_{i} \geq H_{i}^{*}$, the production rate of the $i$ th workstation is out of control; foremen may request the worker at the $i$ th workstation to pace up and reassign workers from other workstations to work at the $i$ th workstation if $n_{i} \geq H_{i}$, or request the worker at the $i$ th workstation to pace down or reassign the worker to other workstations if $p_{i} \geq H_{i}^{*} D_{i, j}$ in Table 2 is a binary parameter. $D_{i, j}=1$ indicates the worker from the ith workstation may be reassigned to work at the $j$ th workstation. $D_{i, j}=0$ indicates the worker from the $i$ th workstation may not be reassigned to work at the $j$ th workstation. The feasibility of reassigning workers from one workstation to the other is subject to the specific tasks performed at workstations, required training for workers, and other policies and rules. It is assumed that one worker is assigned to and works at each workstation in line balancing. In reality, multiple workers may be assigned to a workstation and work as a team. The team may be considered as "one" worker who works at the workstation. $C_{i}$ is the maximum number of workers allowed to be reassigned to work at the ith workstation in addition to the worker who already works at the ith workstation. The worker capacity at a workstation is determined by several factors (e.g., space at a workstation). $n_{i}^{*}$ and $p_{i}^{*}$ in Table 2 are continuous variables representing slack and excess, respectively, in production rate of the $i$ th workstation after line rebalancing. $x_{i, j}$ is a binary variable indicating whether the worker at the $i$ th workstation is reassigned to work at the $i$ th workstation. $y_{i, k}$ is a set of three binary variables $\left(y_{i, 1}, y_{i, 2}\right.$, and $y_{i, 3}$ ) that represent the level of slack in production rate of the $i$ th workstation before line rebalancing. Similarly, $z_{i, k}$ is a set of three binary variables $\left(z_{i, 1}, z_{i, 2}\right.$, and $\left.z_{i, 3}\right)$ that represent the level of excess in production rate of the $i$ th workstation before line rebalancing.

The mathematical model for pace making and worker reassignment is described in (1)-(18). Objection function (1) minimizes the sum of slack and excess in production rates of all workstations after line rebalancing. Constraints (2)-(4) determine whether and how workers may be reassigned from one workstation to another. Constraints (5)-(9) determine the values for three binary variables $\left(y_{i, 1}\right.$ $y_{i, 2}$, and $y_{i, 3}$ ) for each workstation before line rebalancing. These three binary values are determined by the amount of slack in the production rate of each workstation.
Constraint (9) ensures that one and only one of the three binary variables, $y_{i, 1}, y_{i, 2}$, and $y_{i, 3}$, is 1 and the other two are 0 for the ith workstation.

If $y_{i, 1}=1$, the worker at the ith workstation does not pace up nor do workers from other workstations are reassigned to work at the ith workstation. If $y_{i, 2}=1$, constraint (10) determines the slack in production rate of the $i$ th workstation after the worker at the workstation paces up. The maximum percentage of increase in production rate, $g$, varies and depends on assembly lines. Groover [14] suggested that $g=40 \%$. Devotta [12] stated that $100 \%$ pace was the normal pace and the production rate could decrease to $60 \%$ or increase to $140 \%$ of the normal pace. In automotive assembly lines [1], workers may increase the production rate by $20 \%$ of the actual production rate. Foremen may adjust the maximum increase in production rate for line rebalancing. If $y_{i, 3}=1$, constraint (11) determines the slack in production rate of the $i$ th workstation after the worker at the workstation paces up and workers from other workstations are reassigned to work at the workstation. The maximum increase in production rate $\left(g R_{i}+\sum_{j \neq i, j \in I} p_{j} x_{j, i}\right)$ is the outcome of both worker pacing up at the workstation and help from workers reassigned to work at the workstation. Constraints (12)-(18) mirror constraints (5)-(11) and manage excess in production rates. The mathematical model is a mixed integer programming model.

$\min \sum_{i=1}^{|l|}\left(n_{i}^{*}+p_{i}^{*}\right)$

\section{Subject to}

$$
\sum_{j \neq i, j \in I} x_{i, j} \leq 1, \forall i \in I
$$

$$
\sum_{j \neq i, j \in l} x_{j, i} \leq C_{i}, \forall i \in I
$$

$x_{i, j} \leq D_{i, j}, \forall i, j \in I$

$n_{i} y_{i, 1} \leq T_{i}, \forall i \in I$,

$T_{i}\left(1-y_{i, 1}\right) \leq n_{i}, \forall i \in I$

$n_{i}\left(1-y_{i, 3}\right) \leq H_{i}, \forall i \in I$

$H_{i} y_{i, 3} \leq n_{i}, \forall i \in I$ 


$$
\begin{aligned}
& \sum_{k=1}^{3} y_{i, k}=1, \forall i \in I \\
& n_{i}^{*}+g R_{i} y_{i, 2}+M y_{i, 3} \geq n_{i}, \forall i \in I \\
& n_{i}^{*}+g R_{i}+\sum_{j \neq i, j \in I} p_{j} x_{j, i}+M\left(1-y_{i, 3}\right) \geq n_{i}, \forall i \in I \\
& p_{i} z_{i, 1} \leq T_{i}^{*}, \forall i \in I \\
& T_{i}^{*}\left(1-z_{i, 1}\right) \leq p_{i}, \forall i \in I \\
& p_{i}\left(1-z_{i, 3}\right) \leq H_{i}^{*}, \forall i \in I \\
& H_{i}^{*} z_{i, 3} \leq p_{i}, \forall i \in I \\
& \sum_{k=1}^{3} z_{i, k}=1, \forall i \in I \\
& p_{i}^{*}+0.4 R_{i} z_{i, 2}+M z_{i, 3} \geq p_{i}, \forall i \in I \\
& p_{i}^{*}+0.4 R_{i}+\sum_{j \neq i, j \in I} n_{j} x_{j, i}+M\left(1-z_{i, 3}\right) \geq p_{i}, \forall i \in I \\
& n_{i}^{*}, p_{i}^{*} \geq 0, x_{i, j}, y_{i, \mathrm{k}}, z_{i, \mathrm{k}}=0 \text { or } 1, i=1,2, \ldots,|I|, \\
& j=1,2, \ldots,|l|, k=1,2,3
\end{aligned}
$$

A mathematical model's complexity depends on the model detail, which includes the number of feasible solutions, decision variables, and constraints [10]. The complexity of the mathematical model described in (1)-(18) depends on the total number of workstations (|/|) in an assembly line, which determines the numbers of constraints and decision variables in the model. There are $|I|^{2}+16|I|$ constraints and ||$^{2}+8|I|$ decision variables in this mixed integer linear programming model. The order of the complexity of this mathematical model is $\mathrm{O}\left(|/|^{2}\right)$.

\section{Numerical studies and validation}

Production of an unpaced and asynchronous assembly line with multiple workstations may encounter various situations depending on whether and how many workstations have slack or excess in their production rates. To validate the mathematical model described in Sect. 3, seven different scenarios (I-VII) are defined and corresponding case studies are developed and solved. These seven scenarios represent all possible variations in production rates for unpaced and asynchronous assembly lines. Data used in case studies are abstracted from several assembly lines.

Scenario I No slack or excess in production rate of any workstation $\left(n_{i}=p_{i}=0\right)$. The assembly line operates at production rates recommended by line balancing.

Scenario II All workstations have slack in production rates $\left(n_{i}>0\right.$ and $\left.p_{i}=0\right)$; they assemble fewer products than what is required by line balancing. This may happen at the beginning of production or right after the assembly line resumes operations after incidents. The assembly line may be operating in an extended warmup period. Rebalancing of the assembly line may be necessary depending on the level of slack.

Scenario III All workstations have excess in production rates $\left(n_{i}=0\right.$ and $\left.p_{i}>0\right)$; they assemble more products than what is required by line balancing. This may happen due to overreaction in response to slack in production rates or pressure from upstream workstations with excess in production rates. For example, an upstream workstation assembles more products than what is required and pushes products to downstream workstations, which may intentionally or sometimes unintentionally expedite production to absorb the additional products. Rebalancing of the assembly line may be necessary depending on the level of excess.

Scenario IV Some but not all workstations have slack in production rates $\left(n_{i}>0\right.$ and $p_{i}=0$ for some workstations, and $n_{i}=p_{i}=0$ for others). This scenario is similar to Scenario II, but has fewer workstations that have slack in production rates. Rebalancing of the assembly line may be necessary depending on the level of slack. Scenario $V$ Some but not all workstations have excess in production rates $\left(n_{i}=0\right.$ and $p_{i}>0$ for some workstations, and $n_{i}=p_{i}=0$ for others). This scenario is similar to Scenario III, but has fewer workstations that have excess in production rates. Rebalancing of the assembly line may be necessary depending on the level of excess. Scenario VI Some workstations have slack in production rates $\left(n_{i}>0\right.$ and $\left.p_{i}=0\right)$, some have excess in production rates $\left(n_{i}=0\right.$ and $\left.p_{i}>0\right)$, and the others do not have slack or excess in production rates $\left(n_{i}=p_{i}=0\right)$. This scenario describes a common situation of an assembly line with multiple workstations that operate differently with respect to production rates determined by line balancing. Rebalancing of the assembly line may be necessary depending on the level of slack and excess.

Scenario VII Some workstations have slack in production rates $\left(n_{i}>0\right.$ and $\left.p_{i}=0\right)$ and others have excess in production rates $\left(n_{i}=0\right.$ and $\left.p_{i}>0\right)$. This scenario indicates that production rates determined by line bal- 
ancing are not practical and none of the workstations in the assembly line operates at the target production rate. Rebalancing of the assembly line may be necessary depending on the level of slack and excess.

\subsection{Case studies with three and five workstations}

A case study for each of the seven scenarios is developed to validate the mathematical model. An assembly line with three workstations $(i=1,2,3)$ is used in all seven case studies. It is assumed that the production rate determined in line balancing is 100 units per unit time for all three workstations $\left(S_{i}=100, i=1,2,3\right)$. A worker who works at a workstation may be reassigned to work at any of the two other workstations $\left(D_{i j}=1, i=1,2,3, j=1,2,3\right.$, $i \neq j)$. Each workstation may get help from at most one more worker from other workstations $\left(C_{i}=1, i=1,2,3\right)$. Table 3 summarizes the results of the mathematical model for all seven case studies. The General Algebraic Modeling System (GAMS) 24.0.2 is used to solve the mathematical model.

Results in Table 3 show that workers are not reassigned from one workstation to another $\left(x_{i j}=0\right)$. The slacks and excesses in the seven case studies are relatively small. The maximum slack or excess is 10 (Scenarios II-VII). The case studies allow a worker to pace up or pace down as much as $40 \%$ of a workstation's actual production rate $[12,14]$. The relatively small slack and excess may be corrected through pacing up or pacing down by workers; reassignment of workers is not required. The maximum solution time is $0.032 \mathrm{~s}$, indicating that the mathematical model may be used to rebalance small assembly lines in real time.
Table 3 Results of seven case studies

\begin{tabular}{|c|c|c|c|c|c|c|c|c|c|c|c|c|}
\hline Scenario & $\begin{array}{l}\text { Work- } \\
\text { station } \\
i\end{array}$ & $S_{i}$ & $R_{i}$ & $n_{i}$ & $p_{i}$ & $T_{i}$ & $T_{i}^{*}$ & $H_{i}$ & $H_{i}^{*}$ & $\begin{array}{l}\text { Model solution } \\
\text { for rebalancing }\end{array}$ & $\begin{array}{l}\text { Objec- } \\
\text { tive } \\
\text { value }\end{array}$ & $\begin{array}{l}\text { Model solu- } \\
\text { tion time (s) }\end{array}$ \\
\hline \multirow[t]{3}{*}{ I } & 1 & 100 & 100 & 0 & 0 & 5 & 5 & 10 & 10 & \multirow{3}{*}{$\begin{array}{l}x_{i j}=0 \\
n_{i}^{*}=p_{i}^{*}=0\end{array}$} & \multirow[t]{3}{*}{0} & \multirow[t]{3}{*}{0.016} \\
\hline & 2 & 100 & 100 & 0 & 0 & 5 & 5 & 10 & 10 & & & \\
\hline & 3 & 100 & 100 & 0 & 0 & 5 & 5 & 10 & 10 & & & \\
\hline \multirow[t]{6}{*}{ II } & 1 & 100 & 95 & 5 & 0 & 5 & 5 & 10 & 10 & \multirow{6}{*}{$\begin{array}{l}x_{i j}=0 \\
n_{1}^{*}=n_{2}^{*}=0 \\
n_{3}^{*}=1 \\
p_{i}^{*}=0\end{array}$} & \multirow[t]{6}{*}{1} & \multirow[t]{6}{*}{0.032} \\
\hline & & & & & & & & & & & & \\
\hline & & & & & & & & & & & & \\
\hline & & & & & & & & & & & & \\
\hline & 2 & 100 & 90 & 10 & 0 & 5 & 5 & 10 & 10 & & & \\
\hline & 3 & 100 & 99 & 1 & 0 & 5 & 5 & 10 & 10 & & & \\
\hline \multirow[t]{6}{*}{ III } & 1 & 100 & 110 & 0 & 10 & 5 & 5 & 10 & 10 & \multirow{6}{*}{$\begin{array}{l}x_{i j}=0 \\
n_{i}^{*}=0 \\
p_{1}^{*}=p_{2}^{*}=0 \\
p_{3}^{*}=1\end{array}$} & \multirow[t]{6}{*}{1} & \multirow[t]{6}{*}{0.031} \\
\hline & & & & & & & & & & & & \\
\hline & & & & & & & & & & & & \\
\hline & & & & & & & & & & & & \\
\hline & 2 & 100 & 105 & 0 & 5 & 5 & 5 & 10 & 10 & & & \\
\hline & 3 & 100 & 101 & 0 & 1 & 5 & 5 & 10 & 10 & & & \\
\hline \multirow[t]{4}{*}{ IV } & 1 & 100 & 100 & 0 & 0 & 5 & 5 & 10 & 10 & \multirow{4}{*}{$\begin{array}{l}x_{i j}=0 \\
n_{i}^{*}=p_{i}^{*}=0\end{array}$} & \multirow[t]{4}{*}{0} & \multirow[t]{4}{*}{0.032} \\
\hline & & & & & & & & & & & & \\
\hline & 2 & 100 & 95 & 5 & 0 & 5 & 5 & 10 & 10 & & & \\
\hline & 3 & 100 & 90 & 10 & 0 & 5 & 5 & 10 & 10 & & & \\
\hline \multirow[t]{4}{*}{ V } & 1 & 100 & 100 & 0 & 0 & 5 & 5 & 10 & 10 & \multirow{4}{*}{$\begin{array}{l}x_{i j}=0 \\
n_{i}^{*}=p_{i}^{*}=0\end{array}$} & \multirow[t]{4}{*}{0} & \multirow[t]{4}{*}{0.031} \\
\hline & & & & & & & & & & & & \\
\hline & 2 & 100 & 110 & 0 & 10 & 5 & 5 & 10 & 10 & & & \\
\hline & 3 & 100 & 105 & 0 & 5 & 5 & 5 & 10 & 10 & & & \\
\hline \multirow[t]{4}{*}{ VI } & 1 & 100 & 100 & 0 & 0 & 5 & 5 & 10 & 10 & \multirow{4}{*}{$\begin{array}{l}x_{i j}=0 \\
n_{i}^{*}=p_{i}^{*}=0\end{array}$} & \multirow[t]{4}{*}{0} & \multirow[t]{4}{*}{0.031} \\
\hline & & & & & & & & & & & & \\
\hline & 2 & 100 & 110 & 0 & 10 & 5 & 5 & 10 & 10 & & & \\
\hline & 3 & 100 & 90 & 10 & 0 & 5 & 5 & 10 & 10 & & & \\
\hline \multirow[t]{4}{*}{ VII } & 1 & 100 & 95 & 5 & 0 & 5 & 5 & 10 & 10 & \multirow{4}{*}{$\begin{array}{l}x_{i j}=0 \\
n_{i}^{*}=p_{i}^{*}=0\end{array}$} & \multirow[t]{4}{*}{0} & 0.031 \\
\hline & & & & & & & & & & & & \\
\hline & 2 & 100 & 110 & 0 & 10 & 5 & 5 & 10 & 10 & & & \\
\hline & 3 & 100 & 90 & 10 & 0 & 5 & 5 & 10 & 10 & & & \\
\hline
\end{tabular}


Figure 1 shows a case study of five workstations in which worker reassignment helps rebalance an assembly line. Workstation 1 operates as expected according to line balancing. Workstations 2 and 5 have slack in production rate, whereas workstations 3 and 4 have excess in production rate. The mathematical model uses these input data and computes an optimal solution that rebalances the assembly line. The optimal solution suggests workstations 2 and 5 pace up and workstation 3 pace down. Since the slack at workstation 5 exceeds the threshold slack $\left(H_{i}=10\right.$ in Table 3) and the excess at workstation 4 exceeds the threshold excess $\left(H_{i}^{*}=10\right.$ in Table 3 ), the optimal solution to the model also suggests that the worker at workstation 4 be reassigned to workstation 5 .

\subsection{Line rebalancing of one-hundred workstations}

Large assembly lines may include a few dozens of workstations (e.g., automotive assembly lines; [13]. To validate the mathematical model for large assembly lines, two assembly lines of 100 workstations each are rebalanced using the methodology developed in this article. In both assembly lines, a worker who works at a workstation may be reassigned to work at any other workstations $\left(D_{i j}=1\right.$, $i=1, \ldots, 100, j=1, \ldots, 100, i \neq j)$. Each workstation may get help from at most one more worker from other workstations $\left(C_{i}=1, i=1, \ldots, 100\right)$. Without losing generality, it is assumed that the production rate determined in line balancing is 100 units per unit time for all 100 workstations $\left(S_{i}=100, i=1, \ldots, 100\right)$. The data for these two assembly lines are abstracted from literature (e.g., [13] and realworld assembly lines.

The maximum acceptable slack $T_{i}$ and excess $T_{i}^{*}$ in production rates are assumed to be $5\left(T_{i}=T_{i}^{*}=5\right.$, $i=1, \ldots, 100)$. The threshold slack $H_{i}$ and excess $H_{i}^{*}$ in production rate are assumed to be $15\left(H_{i}=H_{i}^{*}=15\right.$, $i=1, \ldots, 100$ ). The actual production rate $R_{i}$ (Appendices 1 and 2 ) is randomly and uniformly generated between 60 (40\% less than 100) and 140 (40\% more than 100$)$. The values for parameters $T_{i}, T_{i}^{*}, H_{i}, H_{i}^{*}$, and $R_{i}$ ensure that (a) some workstations have slack in production rates $\left(n_{i}>0\right)$, some workstations have excess in production rates $\left(p_{i}>0\right)$, and others do not have slack or excess in production rate $\left(n_{i}=p_{i}=0\right)$; (b) among workstations with slack in production rates, some have slack that is acceptable $\left(n_{i} \leq T_{i}\right)$, some have slack that is below the threshold $\left(T_{i} \leq n_{i} \leq H_{i}\right)$ but require pacing up, and others have slack that is above threshold $\left(n_{i} \geq H_{i}\right)$ and require both pacing up and help from workers from other workstations; and (c) among workstations with excess in production

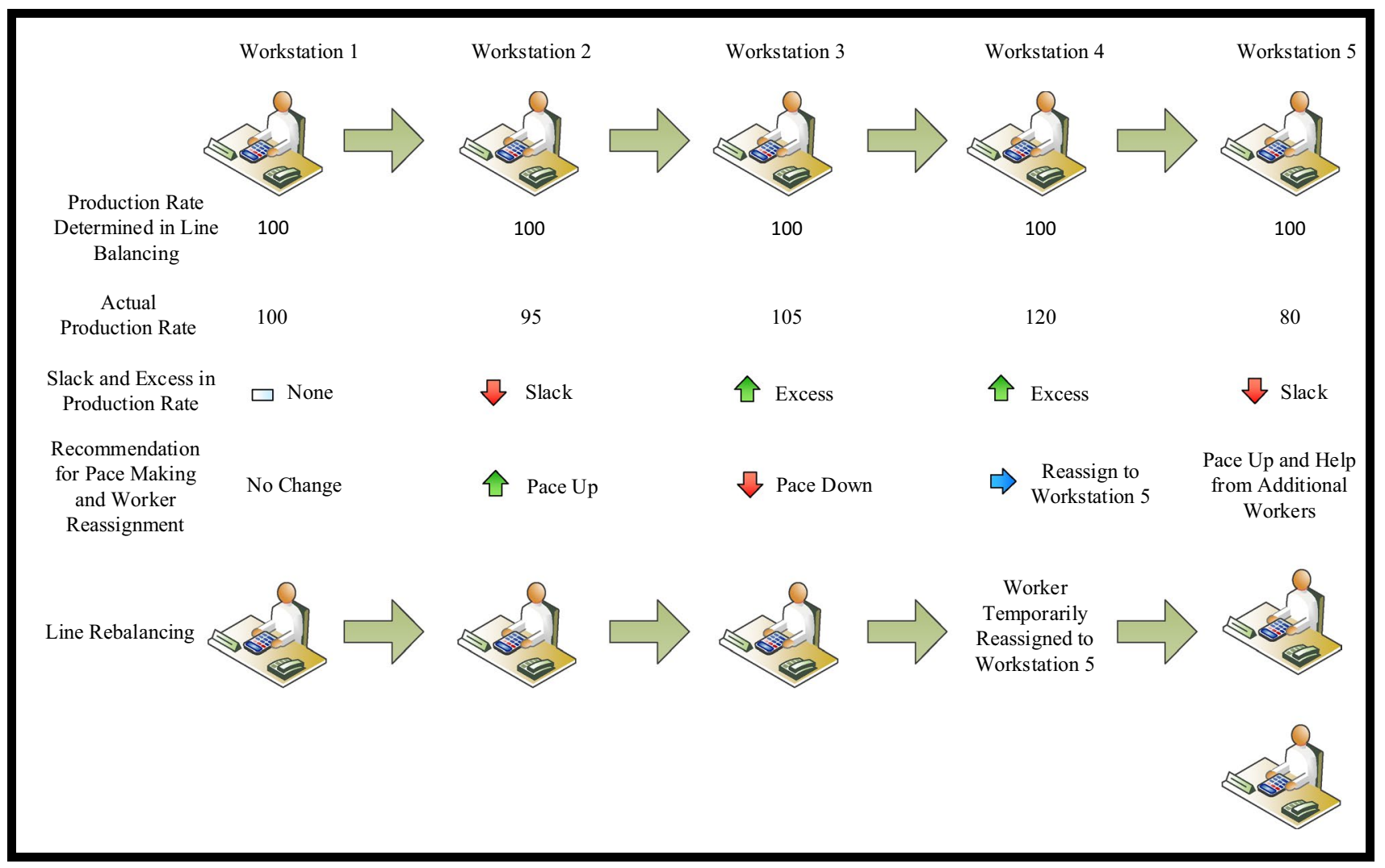

Fig. 1 Line rebalancing of five workstations 
rates, some have excess that is acceptable $\left(p_{i} \leq T_{i}^{*}\right)$, some have excess that is below the threshold $\left(T_{i}^{*} \leq p_{i} \leq H_{i}^{*}\right)$ but require pacing down, and others have excess that is above threshold $\left(p_{i} \geq H_{i}^{*}\right)$ and require pacing down and/or reassigning workers to other workstations. Table 4 summarizes parameter values (Appendix 1) of the first assembly line with 100 workstations, which are divided into seven groups depending on the level of slack and excess in production rates.

Workstations in groups 1, 2, and 5 in Table 4 do not require any actions. Workstations in groups 3 and 4 need to pace up, whereas workstations in groups 6 and 7 need to pace down. In addition, workers who work at workstations in group 7 may be reassigned to workstations in group 4 to increase their production rates. The mathematical model for rebalancing this assembly line of 100 workstations is solved using GAMS 24.0.2 on a desktop computer with 8.00 GB RAM and 64-bit Windows operating system. The solution time is less than one second, indicating the mathematical model developed in Sect. 3 is computationally efficient. Table 5 summarizes worker reassignments from one workstation to the other. For example, the worker at the 18th workstation is reassigned to work at the 24th workstation. Total 10 workers are reassigned from one workstation to another. Table 6 summarizes production rate changes in percentage after pacing up or pacing down. The optimal objective function value is 17 , which is the sum of deviations (slacks and excesses) in production rates of workstations in groups 1,2, and 5 . All other workstations require rebalancing and the model solution ensures that their production rates $R_{i}=S_{i}$ after rebalancing.
Table 7 summarizes parameter values (Appendix 2) of the second assembly line with 100 workstations, which are divided into the same seven groups depending on the level of slack and excess in production rates. The mathematical model for rebalancing this assembly line of 100 workstations is solved using GAMS 24.0.2 on a desktop computer with 8.00 GB RAM and 64-bit Windows operating system. The solution time is again less than one second. Table 8 summarizes worker reassignments from one workstation to the other. Total 12 workers are reassigned from one workstation to another. Table 9 summarizes production rate changes in percentage after pacing up or pacing down.

\subsection{Computational complexity}

The model is implemented in the GAMS 24.0.2 and solved using the CPLEX branch-and-cut algorithm and data extracted from assembly lines. The computational complexity of the branch-and-cut algorithm is difficult to analyze and tight bounds are not available [23]. Table 10 summarizes the solution times of the CPLEX branch-andcut algorithm as the number of workstations increases. Figure 2 shows how solution times in Table 10 changes as the number of workstations increases. The curve in Fig. 2 is best described by a polynomial function with an order of four, indicating that the computational complexity of solving the mathematical model is $O\left(|/|^{4}\right)$.

Table 4 Slacks and excesses in production rates of one-hundred workstations (Appendix 1)

\begin{tabular}{lllr}
\hline Group & Slack $\left(n_{i}\right)$ and excess $\left(p_{i}\right)$ & Workstations $(i)$ & $\begin{array}{c}\text { Number of } \\
\text { workstations }\end{array}$ \\
\hline 1 & $n_{i}=p_{i}=0$ & $3,77,97$ & 3 \\
2 & $n_{i} \leq T_{i}$ and $p_{i}=0$ & $1,44,49,66,78$ & 5 \\
3 & $T_{i} \leq n_{i} \leq H_{i}$ and $p_{i}=0$ & $4,12,20,25,27,33,42,43,52,59,61,64,83,85,89,93,100$ & 17 \\
4 & $n_{i} \geq H_{i}$ and $p_{i}=0$ & $5,6,11,21,22,24,36,37,46,47,50,55,68,69,70,71,74,75,76,86,88,92,94,95,96,98$ & 26 \\
5 & $p_{i} \leq T_{i}^{*}$ and $n_{i}=0$ & 34,35 & 2 \\
6 & $T_{i}^{*} \leq p_{i} \leq H_{i}^{*}$ and $n_{i}=0$ & $10,16,18,30,48,51,54,60,65$ & 9 \\
7 & $p_{i} \geq H_{i}^{*}$ and $n_{i}=0$ & $2,7,8,9,13,14,15,17,19,23,26,28,29,31,32,38,39,40,41,45,53,56,57,58,62,63$, & 38 \\
& & $67,72,73,79,80,81,82,84,87,90,91,99$ & 100 \\
Total & & &
\end{tabular}

Table 5 Worker reassignment for the assembly line of one-hundred workstations (Appendix 1)

Worker reassignment between workstations
\begin{tabular}{llllllllll}
$18 \rightarrow 24$ & $32 \rightarrow 36$ & $41 \rightarrow 95$ & $56 \rightarrow 5$ & $57 \rightarrow 6$ & $58 \rightarrow 68$ & $62 \rightarrow 94$ & $63 \rightarrow 98$ & $67 \rightarrow 88$ & $81 \rightarrow 37$ \\
\hline
\end{tabular}


Table 6 Production rate changes for the assembly line of one-hundred workstations (Appendix 1)

\begin{tabular}{|c|c|c|c|c|c|c|}
\hline Action & Workstation & $\begin{array}{l}\text { Production } \\
\text { rate change } \\
(\%)\end{array}$ & Workstation & $\begin{array}{l}\text { Production } \\
\text { Rate change } \\
(\%)\end{array}$ & Workstation & $\begin{array}{l}\text { Production } \\
\text { Rate change } \\
(\%)\end{array}$ \\
\hline \multirow[t]{13}{*}{ Pace up } & 4 & 0.124 & 5 & 0.355 & 6 & 0.274 \\
\hline & 11 & 0.190 & 12 & 0.111 & 20 & 0.136 \\
\hline & 21 & 0.250 & 22 & 0.351 & 24 & 0.400 \\
\hline & 25 & 0.111 & 27 & 0.149 & 33 & 0.087 \\
\hline & 42 & 0.064 & 43 & 0.111 & 46 & 0.299 \\
\hline & 47 & 0.351 & 50 & 0.389 & 52 & 0.099 \\
\hline & 55 & 0.351 & 59 & 0.087 & 61 & 0.087 \\
\hline & 64 & 0.087 & 68 & 0.238 & 69 & 0.205 \\
\hline & 70 & 0.176 & 71 & 0.299 & 74 & 0.316 \\
\hline & 75 & 0.250 & 76 & 0.250 & 83 & 0.053 \\
\hline & 85 & 0.064 & 86 & 0.299 & 89 & 0.136 \\
\hline & 92 & 0.333 & 93 & 0.124 & 94 & 0.049 \\
\hline & 96 & 0.316 & 100 & 0.111 & & \\
\hline \multirow[t]{15}{*}{ Pace down } & 2 & -0.237 & 7 & -0.160 & 8 & -0.237 \\
\hline & 9 & -0.145 & 10 & -0.048 & 13 & -0.206 \\
\hline & 14 & -0.254 & 15 & -0.225 & 16 & -0.099 \\
\hline & 17 & -0.265 & 18 & -0.083 & 19 & -0.275 \\
\hline & 23 & -0.242 & 26 & -0.270 & 28 & -0.275 \\
\hline & 29 & -0.194 & 30 & -0.065 & 31 & -0.254 \\
\hline & 32 & -0.030 & 38 & -0.248 & 39 & -0.180 \\
\hline & 40 & -0.265 & 41 & -0.281 & 45 & -0.231 \\
\hline & 48 & -0.115 & 51 & -0.107 & 53 & -0.160 \\
\hline & 54 & -0.057 & 60 & -0.048 & 63 & -0.021 \\
\hline & 65 & -0.091 & 67 & -0.022 & 72 & -0.237 \\
\hline & 73 & -0.286 & 79 & -0.206 & 80 & -0.145 \\
\hline & 81 & -0.022 & 82 & -0.242 & 84 & -0.265 \\
\hline & 87 & -0.248 & 90 & -0.153 & 91 & -0.270 \\
\hline & 99 & -0.281 & & & & \\
\hline
\end{tabular}

Table 7 Slacks and excesses in production rates of one-hundred workstations (Appendix 2)

\begin{tabular}{|c|c|c|c|}
\hline Group & Slack $\left(n_{i}\right)$ and excess $\left(p_{i}\right)$ & Workstations (i) & $\begin{array}{l}\text { Number of } \\
\text { Workstations }\end{array}$ \\
\hline 1 & $n_{i}=p_{i}=0$ & None & 0 \\
\hline 2 & $n_{i} \leq T_{i}$ and $p_{i}=0$ & $7,18,20,32,45,79$ & 6 \\
\hline 3 & $T_{i} \leq n_{i} \leq H_{i}$ and $p_{i}=0$ & $1,2,3,5,8,9,10,14,25,27,43,52,56,78,89,98,100$ & 17 \\
\hline 4 & $n_{i} \geq H_{i}$ and $p_{i}=0$ & $\begin{array}{l}11,13,19,23,29,31,40,41,47,50,53,54,66,67,68,70,73,81,82,85,86,87,91,92,94,95 \\
99\end{array}$ & 27 \\
\hline 5 & $p_{i} \leq T_{i}^{*}$ and $n_{i}=0$ & $48,63,77,80,96,97$ & 6 \\
\hline 6 & $T_{i}^{*} \leq p_{i} \leq H_{i}^{*}$ and $n_{i}=0$ & $12,15,30,34,37,44,55,59,64,69,76,83$ & 12 \\
\hline 7 & $p_{i} \geq H_{i}^{*}$ and $n_{i}=0$ & $\begin{array}{l}4,6,16,17,21,22,24,26,28,33,35,36,38,39,42,46,49,51,57,58,60,61,62,65,71,72 \\
\quad 74,75,84,88,90,93\end{array}$ & 32 \\
\hline Total & & & 100 \\
\hline
\end{tabular}

Table 8 Worker reassignment for the assembly line of one-hundred workstations (Appendix 2)

\begin{tabular}{|c|c|c|c|c|c|c|c|c|c|c|c|}
\hline \multicolumn{12}{|c|}{ Worker reassignment between workstations } \\
\hline $4 \rightarrow 66$ & $12 \rightarrow 86$ & $21 \rightarrow 99$ & $35 \rightarrow 70$ & $51 \rightarrow 68$ & $55 \rightarrow 31$ & $60 \rightarrow 40$ & $61 \rightarrow 53$ & $62 \rightarrow 29$ & $64 \rightarrow 73$ & $65 \rightarrow 11$ & $88 \rightarrow 67$ \\
\hline
\end{tabular}


Table 9 Production rate changes for the assembly line of one-hundred workstations (Appendix 2)

\begin{tabular}{|c|c|c|c|c|c|c|}
\hline Action & Workstation & $\begin{array}{l}\text { Production } \\
\text { rate change } \\
(\%)\end{array}$ & Workstation & $\begin{array}{l}\text { Production } \\
\text { rate change } \\
(\%)\end{array}$ & Workstation & $\begin{array}{l}\text { Production } \\
\text { rate change } \\
\text { (\%) }\end{array}$ \\
\hline \multirow[t]{15}{*}{ Pace up } & 1 & 0.176 & 2 & 0.075 & 3 & 0.111 \\
\hline & 5 & 0.176 & 8 & 0.124 & 9 & 0.124 \\
\hline & 10 & 0.124 & 11 & 0.056 & 13 & 0.190 \\
\hline & 14 & 0.111 & 19 & 0.282 & 20 & 0.053 \\
\hline & 23 & 0.333 & 25 & 0.124 & 27 & 0.075 \\
\hline & 29 & 0.187 & 31 & 0.225 & 40 & 0.361 \\
\hline & 41 & 0.370 & 43 & 0.163 & 45 & 0.053 \\
\hline & 47 & 0.351 & 50 & 0.282 & 52 & 0.176 \\
\hline & 53 & 0.167 & 54 & 0.389 & 56 & 0.099 \\
\hline & 66 & 0.048 & 67 & 0.016 & 70 & 0.254 \\
\hline & 73 & 0.381 & 78 & 0.087 & 81 & 0.250 \\
\hline & 82 & 0.389 & 85 & 0.266 & 86 & 0.225 \\
\hline & 87 & 0.266 & 89 & 0.163 & 91 & 0.282 \\
\hline & 92 & 0.282 & 94 & 0.316 & 95 & 0.220 \\
\hline & 98 & 0.111 & 99 & 0.029 & 100 & 0.136 \\
\hline \multirow[t]{13}{*}{ Pace down } & 6 & -0.174 & 12 & -0.115 & 15 & -0.091 \\
\hline & 16 & -0.153 & 17 & -0.219 & 22 & -0.153 \\
\hline & 24 & -0.219 & 26 & -0.237 & 28 & -0.145 \\
\hline & 30 & -0.115 & 33 & -0.231 & 34 & -0.065 \\
\hline & 36 & -0.231 & 37 & -0.065 & 38 & -0.138 \\
\hline & 39 & -0.187 & 42 & -0.174 & 44 & -0.130 \\
\hline & 46 & -0.174 & 48 & -0.048 & 49 & -0.200 \\
\hline & 51 & -0.022 & 55 & -0.115 & 57 & -0.200 \\
\hline & 58 & -0.180 & 59 & -0.099 & 64 & -0.115 \\
\hline & 69 & -0.091 & 71 & -0.153 & 72 & -0.160 \\
\hline & 74 & -0.206 & 75 & -0.242 & 76 & -0.130 \\
\hline & 83 & -0.115 & 84 & -0.270 & 90 & -0.180 \\
\hline & 93 & -0.242 & 97 & -0.048 & & \\
\hline
\end{tabular}

\begin{tabular}{lllllllll}
\hline Number of Workstations & 3 & 5 & 10 & 50 & 100 & 250 & 500 & 1000 \\
\hline Solution time (s) & 0.016 & 0.032 & 0.064 & 0.350 & 0.950 & 1.500 & 1.900 & 2.520
\end{tabular}

Table 10 Solution times of the mathematical model line foremen with real-time recommendations for line rebalancing.

Parameters of the mathematical model are obtained from line balancing and assembly line operations. When production rates of workstations deviate from predetermined values, foremen use the parameters as input and run the mathematical model to find the optimal worker reassignment and production rate adjustment in real time. Foremen use the optimal solution of the mathematical model and make informed decisions about how workers may be reassigned between workstations and how production rates should be adjusted to minimize the impact of various disturbances that are unavoidable in assembly lines. 


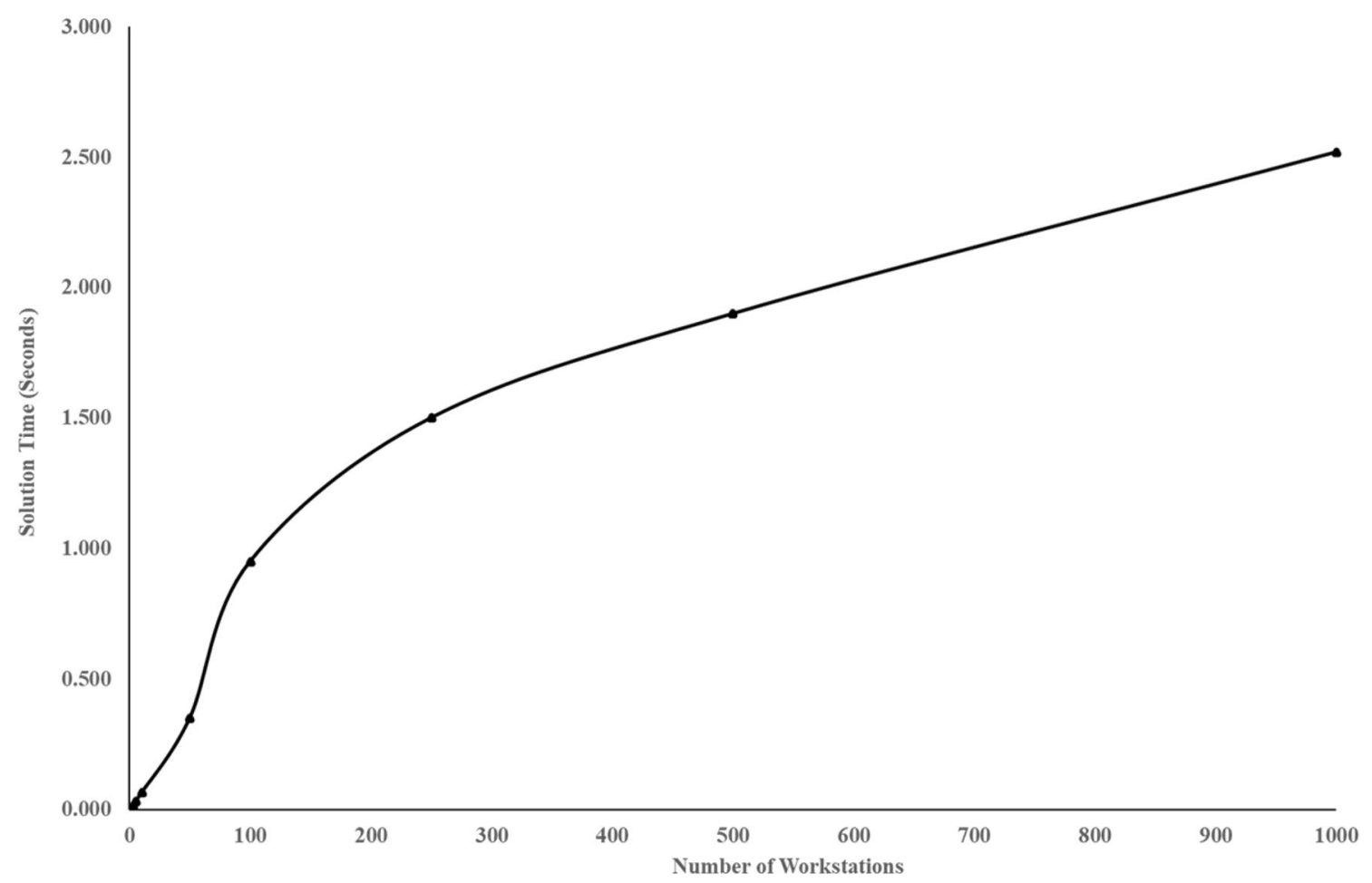

Fig. 2 Solutions times (Table 10) of the mathematical model

Assembly line foremen may also determine the maximum allowable increase (pacing up) and decrease (pacing down) for each workstation. Larger increase and decrease help smooth workload among workstations. This may be feasible at the beginning of a shift when workers are more flexible in productivity. Smaller increase and decrease limit workstations' ability to smooth workload through pacing up or pacing down; more workers are reassigned between workstations to reduce the impact of disturbances. This becomes likely toward the end of a shift when workers experience fatigue, or for a shift in which most workers have limited experience with assembly tasks. The mathematical model enables foremen to adjust the maximum allowable increase and decrease in production rates and optimally control the assembly line with realistic solutions.

Future research may incorporate and implement the mathematical model in a decision support system with a user-friendly interface for assembly line foremen to interact with the model and make informed decisions. The model developed in this article focuses on production systems and assembly lines. In the future, the mathematical model may be revised and expanded for service systems, which face unique challenges such as highly stochastic demand, and the need to minimize customer wait time and maximize the number of customers served. In addition, the methodology developed in this article may be generalized to solve other task assignment and realtime reassignment problems. Another promising research direction is to use the branch, bound, and remember method [17] to tackle the line rebalancing problem.

Availability of data and material Data are included in appendices

\section{Compliance with ethical standards}

Conflict of interest Not applicable

\section{Appendix 1}

Actual production rates $\left(R_{i}^{\prime} s\right)$ and corresponding slacks $\left(n_{i}^{\prime} s\right)$ and excesses $\left(p_{i}^{\prime} s\right)$ of the first assembly line of onehundred workstations $(i=1, \ldots, 100)$ 


\begin{tabular}{rrrrrrrrrrrrrrrrr}
\hline$i$ & \multicolumn{1}{c}{$R_{i}$} & \multicolumn{1}{c}{$n_{i}$} & \multicolumn{1}{c}{$p_{i}$} & \multicolumn{1}{c}{$R_{i}$} & \multicolumn{1}{c}{$n_{i}$} & \multicolumn{1}{c}{$p_{i}$} & \multicolumn{1}{c}{$R_{i}$} & $n_{i}$ & $p_{i}$ & $i$ & $R_{i}$ & $n_{i}$ & $p_{i}$ \\
\hline 1 & 97 & 3 & 0 & 26 & 137 & 0 & 37 & 51 & 112 & 0 & 12 & 76 & 80 & 20 & 0 \\
2 & 131 & 0 & 31 & 27 & 87 & 13 & 0 & 52 & 91 & 9 & 0 & 77 & 100 & 0 & 0 \\
3 & 100 & 0 & 0 & 28 & 138 & 0 & 38 & 53 & 119 & 0 & 19 & 78 & 99 & 1 & 0 \\
4 & 89 & 11 & 0 & 29 & 124 & 0 & 24 & 54 & 106 & 0 & 6 & 79 & 126 & 0 & 26 \\
5 & 62 & 38 & 0 & 30 & 107 & 0 & 7 & 55 & 74 & 26 & 0 & 80 & 117 & 0 & 17 \\
6 & 62 & 38 & 0 & 31 & 134 & 0 & 34 & 56 & 116 & 0 & 16 & 81 & 134 & 0 & 34 \\
7 & 119 & 0 & 19 & 32 & 134 & 0 & 34 & 57 & 121 & 0 & 21 & 82 & 132 & 0 & 32 \\
8 & 131 & 0 & 31 & 33 & 92 & 8 & 0 & 58 & 122 & 0 & 22 & 83 & 95 & 5 & 0 \\
9 & 117 & 0 & 17 & 34 & 103 & 0 & 3 & 59 & 92 & 8 & 0 & 84 & 136 & 0 & 36 \\
10 & 105 & 0 & 5 & 35 & 101 & 0 & 1 & 60 & 105 & 0 & 5 & 85 & 94 & 6 & 0 \\
11 & 84 & 16 & 0 & 36 & 70 & 30 & 0 & 61 & 92 & 8 & 0 & 86 & 77 & 23 & 0 \\
12 & 90 & 10 & 0 & 37 & 69 & 31 & 0 & 62 & 136 & 0 & 36 & 87 & 133 & 0 & 33 \\
13 & 126 & 0 & 26 & 38 & 133 & 0 & 33 & 63 & 140 & 0 & 40 & 88 & 69 & 31 & 0 \\
14 & 134 & 0 & 34 & 39 & 122 & 0 & 22 & 64 & 92 & 8 & 0 & 89 & 88 & 12 & 0 \\
15 & 129 & 0 & 29 & 40 & 136 & 0 & 36 & 65 & 110 & 0 & 10 & 90 & 118 & 0 & 18 \\
16 & 111 & 0 & 11 & 41 & 139 & 0 & 39 & 66 & 97 & 3 & 0 & 91 & 137 & 0 & 37 \\
17 & 136 & 0 & 36 & 42 & 94 & 6 & 0 & 67 & 134 & 0 & 34 & 92 & 75 & 25 & 0 \\
18 & 109 & 0 & 9 & 43 & 90 & 10 & 0 & 68 & 63 & 37 & 0 & 93 & 89 & 11 & 0 \\
19 & 138 & 0 & 38 & 44 & 98 & 2 & 0 & 69 & 83 & 17 & 0 & 94 & 61 & 39 & 0 \\
20 & 88 & 12 & 0 & 45 & 130 & 0 & 30 & 70 & 85 & 15 & 0 & 95 & 64 & 36 & 0 \\
21 & 80 & 20 & 0 & 46 & 77 & 23 & 0 & 71 & 77 & 23 & 0 & 96 & 76 & 24 & 0 \\
22 & 74 & 26 & 0 & 47 & 74 & 26 & 0 & 72 & 131 & 0 & 31 & 97 & 100 & 0 & 0 \\
23 & 132 & 0 & 32 & 48 & 113 & 0 & 13 & 73 & 140 & 0 & 40 & 98 & 63 & 37 & 0 \\
24 & 65 & 35 & 0 & 49 & 96 & 4 & 0 & 74 & 76 & 24 & 0 & 99 & 139 & 0 & 39 \\
25 & 90 & 10 & 0 & 50 & 72 & 28 & 0 & 75 & 80 & 20 & 0 & 100 & 90 & 10 & 0 \\
\hline
\end{tabular}

\section{Appendix 2}

Actual production rates $\left(R_{i}^{\prime} s\right)$ and corresponding slacks $\left(n_{i}^{\prime} s\right)$ and excesses $\left(p_{i}^{\prime} s\right)$ of the second assembly line of one-hundred workstations $(i=1, \ldots, 100)$

\begin{tabular}{rrrrlrrrlrrrrrrr}
\hline$i$ & \multicolumn{1}{c}{$R_{i}$} & \multicolumn{1}{c}{$n_{i}$} & \multicolumn{1}{c}{$p_{i}$} & $i$ & \multicolumn{1}{c}{$R_{i}$} & \multicolumn{1}{c}{$n_{i}$} & \multicolumn{1}{c}{$p_{i}$} & \multicolumn{1}{c}{$i$} & \multicolumn{1}{c}{$R_{i}$} & $n_{i}$ & \multicolumn{1}{c}{$p_{i}$} & $i$ & $R_{i}$ & $n_{i}$ & $p_{i}$ \\
\hline 1 & 85 & 15 & 0 & 26 & 131 & 0 & 31 & 51 & 137 & 0 & 37 & 76 & 115 & 0 & 15 \\
2 & 93 & 7 & 0 & 27 & 93 & 7 & 0 & 52 & 85 & 15 & 0 & 77 & 101 & 0 & 1 \\
3 & 90 & 10 & 0 & 28 & 117 & 0 & 17 & 53 & 66 & 34 & 0 & 78 & 92 & 8 & 0 \\
4 & 134 & 0 & 34 & 29 & 64 & 36 & 0 & 54 & 72 & 28 & 0 & 79 & 98 & 2 & 0 \\
5 & 85 & 15 & 0 & 30 & 113 & 0 & 13 & 55 & 113 & 0 & 13 & 80 & 103 & 0 & 3 \\
6 & 121 & 0 & 21 & 31 & 71 & 29 & 0 & 56 & 91 & 9 & 0 & 81 & 80 & 20 & 0 \\
7 & 97 & 3 & 0 & 32 & 97 & 3 & 0 & 57 & 125 & 0 & 25 & 82 & 72 & 28 & 0 \\
8 & 89 & 11 & 0 & 33 & 130 & 0 & 30 & 58 & 122 & 0 & 22 & 83 & 113 & 0 & 13 \\
9 & 89 & 11 & 0 & 34 & 107 & 0 & 7 & 59 & 111 & 0 & 11 & 84 & 137 & 0 & 37 \\
10 & 89 & 11 & 0 & 35 & 116 & 0 & 16 & 60 & 117 & 0 & 17 & 85 & 79 & 21 & 0 \\
11 & 71 & 29 & 0 & 36 & 130 & 0 & 30 & 61 & 123 & 0 & 23 & 86 & 71 & 29 & 0 \\
12 & 113 & 0 & 13 & 37 & 107 & 0 & 7 & 62 & 124 & 0 & 24 & 87 & 79 & 21 & 0 \\
13 & 84 & 16 & 0 & 38 & 116 & 0 & 16 & 63 & 104 & 0 & 4 & 88 & 137 & 0 & 37 \\
14 & 90 & 10 & 0 & 39 & 123 & 0 & 23 & 64 & 113 & 0 & 13 & 89 & 86 & 14 & 0 \\
15 & 110 & 0 & 10 & 40 & 61 & 39 & 0 & 65 & 125 & 0 & 25 & 90 & 122 & 0 & 22 \\
\hline
\end{tabular}




\begin{tabular}{|c|c|c|c|c|c|c|c|c|c|c|c|c|c|c|c|}
\hline$i$ & $R_{i}$ & $n_{i}$ & $p_{i}$ & $i$ & $R_{i}$ & $n_{i}$ & $p_{i}$ & $i$ & $R_{i}$ & $n_{i}$ & $p_{i}$ & $i$ & $R_{i}$ & $n_{i}$ & $p_{i}$ \\
\hline$\overline{16}$ & 118 & 0 & 18 & 41 & 73 & 27 & 0 & 66 & 63 & 37 & 0 & 91 & 78 & 22 & 0 \\
\hline 17 & 128 & 0 & 28 & 42 & 121 & 0 & 21 & 67 & 62 & 38 & 0 & 92 & 78 & 22 & 0 \\
\hline 18 & 96 & 4 & 0 & 43 & 86 & 14 & 0 & 68 & 66 & 34 & 0 & 93 & 132 & 0 & 32 \\
\hline 19 & 78 & 22 & 0 & 44 & 115 & 0 & 15 & 69 & 110 & 0 & 10 & 94 & 76 & 24 & 0 \\
\hline 20 & 95 & 5 & 0 & 45 & 95 & 5 & 0 & 70 & 67 & 33 & 0 & 95 & 82 & 18 & 0 \\
\hline 21 & 128 & 0 & 28 & 46 & 121 & 0 & 21 & 71 & 118 & 0 & 18 & 96 & 103 & 0 & 3 \\
\hline 22 & 118 & 0 & 18 & 47 & 74 & 26 & 0 & 72 & 119 & 0 & 19 & 97 & 105 & 0 & 5 \\
\hline 23 & 75 & 25 & 0 & 48 & 105 & 0 & 5 & 73 & 63 & 37 & 0 & 98 & 90 & 10 & 0 \\
\hline 24 & 128 & 0 & 28 & 49 & 125 & 0 & 25 & 74 & 126 & 0 & 26 & 99 & 70 & 30 & 0 \\
\hline 25 & 89 & 11 & 0 & 50 & 78 & 22 & 0 & 75 & 132 & 0 & 32 & 100 & 88 & 12 & 0 \\
\hline
\end{tabular}

\section{References}

1. Alfaro-Pozo R, Bautista-Valhondo J (2018) An expert system to minimize operational costs in mixed-model sequencing problems with activity factor. Expert Systems Appl 104(15):185-201

2. Antoine M, Hind BEH, Wahiba RCK, Lounes BM (2016) Iterated local search for dynamic assembly line rebalancing problem. Int Fed Autom Control 49(12):515-519

3. Battaïa O, Delorme X, Dolgui A, Hagemann J, Horlemann A, Kovalev S, Malyutin S (2015) Workforce minimization for a mixed-model assembly line in the automotive industry. Int J Prod Econ 170:489-500

4. Battini D, Calzavara M, Otto A, Sgarbossa F (2016) The integrated assembly line balancing and parts feeding problem with ergonomics considerations. IFAC-PapersOnLine 49(12):191-196

5. Bautista J, Alfaro-Pozo R, Batalla-García C (2015) Consideration of human resources in the mixed-model sequencing problem with work overload minimization: legal provisions and productivity improvement. Expert Syst Appl 42(22):8896-8910

6. Becker C, Scholl A (2006) A survey on problems and methods in generalized assembly line balancing. Eur J Oper Res 168:694-715

7. Boysen N, Fliedner M, Scholl A (2007) A classification of assembly line balancing problems. Eur J Oper Res 183:674-693

8. Boysen N, Fliedner M, Scholl A (2008) Assembly line balancing: which model to use when? Int J Prod Econ 111:509-528

9. Boysen N, Fliedner M, Scholl A (2009) Sequencing mixed-model assembly lines: survey, classification and model critique. Eur J Oper Res 192:349-373

10. Brooks RJ, Tobias AM (1996) Choosing the best model: level of detail, complexity, and model performance. Math Comput Model 24(4):1-14

11. Buyukozkan K, Kucukkoc I, Satoglu SI, Zhang DZ (2016) Lexicographic bottleneck mixed-model assembly line balancing problem: artificial bee colony and tabu search approaches with optimised parameters. Expert Syst Appl 50(15):151-166

12. Devotta AF (1988) A survey of performance rating research in work measurement, Ph.D. Thesis, Department of Industrial Engineering, Kansas State University, Manhattan, Kansas

13. Grangeon N, Leclaire $P$, Norre $S$ (2011) Heuristics for the re-balancing of a vehicle assembly line. Int J Prod Res 49:6609-6628

14. Groover MP (2007) Work systems and the methods, measurement, and management of work. Upper Saddle River, Pearson Prentice Hall, pp 27-46

15. Kara Y, Ozcan U, Peker A (2007) Balancing and sequencing mixed-model just-in-time U-lines with multiple objectives. Appl Math Comput 184(2):566-588
16. Li Y, Boucher TO (2017) Assembly line balancing problem with task learning and dynamic task reassignment. Int J Adv Manuf Technol 88:3089-3097

17. Li Z, Çil ZA, Mete S, Kucukkoc I (2019) A fast branch, bound and remember algorithm for disassembly line balancing problem. Int J Prod Res 58(11):3220-3234

18. Li Z, Kucukkoc I, Tang Q (2019) A comparative study of exact methods for the simple assembly line balancing problem. Soft Comput. https://doi.org/10.1007/s00500-019-04609-9

19. Li Z, Janardhanan MN, Rahman HF (2020) Enhanced beam search heuristic for U-shaped assembly line balancing problems. J Eng Optim. https://doi.org/10.1080/0305215X.2020.1741569

20. Malachowski B, Korytkowski P (2018) Competence-based workforce allocation for manual assembly lines. In: International conference on intelligent systems in production engineering and maintenance, pp. 442-451, Wrocław, Poland

21. Manavizadeh N, Rabbani M, Moshtaghi D, Jolai F (2012) Mixedmodel assembly line balancing in the make-to-order and stochastic environment using multi-objective evolutionary algorithms. Expert Syst Appl 39(15):12026-12031

22. Manceaux A, El-Haouzi HB, Thomas A, Pétin JF (2014) Dynamic rebalancing of an assembly line with a reachability analysis of communicating automata. In: International conference on advances in production management systems, Ajaccio, France

23. Mitchell JE (2008) Integer programming: branch and cut algorithm. In: Floudas C, Pardalos P (eds) Encyclopedia of optimization. Springer, Boston

24. Miltenburg J (2002) Balancing and scheduling mixed-model U-shaped production lines. Int J Flex Manuf Syst 14:119-151

25. Mishan NN, Tap MM (2015) Increasing line efficiency by using time study and line balancing in a food manufacturing company. Jurnal Mekanikal 38:32-43

26. Öner-Közen M, Minner S, Steinthaler F (2017) Efficiency of paced and unpaced assembly lines under consideration of worker variability - A simulation study. Comput Ind Eng 111:516-526

27. Otto A, Scholl A (2011) Incorporating ergonomic risks into assembly line balancing. Eur J Oper Res 212(2):277-286

28. Raj AV, Mathew J, Jose P, Sivan G (2016) Optimization of cycle time in an assembly line balancing problem. Procedia Technol 25:1146-1153

29. Rosenblatt MJ, Carlson RC (1985) Designing a production line to maximize profit. IIE Trans 17(2):117-122

30. Scholl A, Becker C (2006) State-of-the-art exact and heuristic solution procedures for simple assembly line balancing. Eur J Oper Res 168:666-693 
31. Smunt TL, Perkins WC (1985) Stochastic unpaced line design: review and further experimental results. J Oper Manag 5(3):351-373

32. Toksarı MD, İşleyen SK, Güner E, Baykoç ÖF (2010) Assembly line balancing problem with deterioration tasks and learning effect. Expert Syst Appl 37(2):1223-1228

33. Walker CR, Guest RH, Turner AN (2017) The Foreman on the assembly line. Routledge, Abingdon

34. Wellington J, Lewis SA (2018) Interactive excel-based procedure for line balancing. (INFORMS) Trans Educ 19(1):23-35

35. Yagmahan B (2011) Mixed-model assembly line balancing using a multi-objective ant colony optimization approach. Expert Syst Appl 38(10):12453-12461
36. Yang C, Gao J, Sun L (2013) A multi-objective genetic algorithm for mixed-model assembly line rebalancing. Comput Ind Eng 65(1):109-116

37. Zhang Z, Wang K, Zhu L, Wang Y (2017) A Pareto improved artificial fish swarm algorithm for solving a multi-objective fuzzy disassembly line balancing problem. Expert Syst Appl 86(15):165-176

38. Zhang Y, Hu X, Wu C (2018) A modified multi-objective genetic algorithm for two-sided assembly line re-balancing problem of a shovel loader. Int J Prod Res 56(9):3043-3063

Publisher's Note Springer Nature remains neutral with regard to jurisdictional claims in published maps and institutional affiliations. 